\title{
Cross-cultural Management of Multinational Companies in China
}

\author{
Lihong Wang ${ }^{1, a^{*}}$, Weijie Gou ${ }^{2, b}$ \\ ${ }^{1}$ Beijing Polytechnic, Department Of English Teaching, Beijing China 100176 \\ ${ }^{2}$ Beijing Polytechnic, School of Automotive Engineering, Beijing China 100176 \\ awlhjane@126.coml, bgvjie@126.com,
}

Keywords: Cross-cultural management; Multinational companies; Cultural differences; Cultural conflicts

\begin{abstract}
As cross-cultural management in multinational companies is a complex topic, it's important to explore the deep reasons behind; Documentary research in this thesis is mainly about the literature review concerning different cultural patterns.
\end{abstract}

\section{Introduction}

Transnational operation is a very common phenomenon in today's economic world. In order to obtain the maximum economic benefits, companies must go beyond national boundary, and allocate the essential factors of production optimally in the whole world. When enterprises operate beyond border, they confront the totally different culture from their motherland, and the transnational operating circumstances are mainly determined by the cultural differences.

With rapid progress of globalization, there is more and stronger co-operation between nations. More and more Multinational companies come to China, and China's companies will also go beyond border to operate. This needs our scholars to study cross-cultural management theory more actively, and put forward more applicable theory. Therefore, the overall objective of this thesis is to build a bridge between foreign culture and Chinese traditional culture, through which transnational companies can fit into China's economic and cultural circumstances quickly and smoothly, and China can also adapt to international economic environment.

\section{Basic Concepts and Theories}

Multinational Companies. In 1983 the Center of Multinational Companies in the United Nations published the third survey about " The Developing Multinational Companies in the World", in which a Multinational Company is defined as follows: it includes corporate entities in two or more than two countries, and it doesn't matter what kind of legal form the entities apply and in what field they operate; It operates within one decision-making system, and can take concerted countermeasures and common strategy through one or several decision-making centers; The entities form contacts through equity or other forms, thus one or several of the entities can exert significant influence on other ones, especially share knowledge resources and responsibilities with them

Cultural Conflicts. Cultural conflicts can be known from two aspects. First is inside the company, when enterprises engage in transnational operation, they usually employ local people to realize localization. Second is outside the company, after multinational companies enter host countries, they will be influenced by the cultural environment of the host countries. Seen from inside, the conflicts among employees usually cause poor corporate management and low efficiency, thus increase the operation cost. Seen from outside, because of the conflicts between the cultural environment of the host country and the corporate culture, the enterprises and their operation are usually boycotted by the people, and even by the government and relevant departments of the host country.

The causes of the cultural conflicts encountered by multinational companies can be summarized as the following aspects: 
Cultural conflicts caused by language and way of communication: The difference of languages, deep meaning of the text and mode of communication causes misunderstanding, and then leads to cultural conflicts. Modes of communication, whether verbal or non-verbal, can separate people with different culture from each other. Language is not only the collection of words and sentences, it also express the mode of thinking of a culture. Therefore, mastering a language is the key to understand the culture it reflects.

Because different enterprises are founded and developed in different circumstances, people have different ways to describe and express even the same thing. When people talk about the same thing, usually they only communicate literally, and can not express exactly with language about the customs which are included in deep layer and formed during production practice of different countries, districts and nationalities, and this plants seeds for the cultural conflicts. If the multinational companies do not coordinate towards it correctly and timely during operation, severe cultural conflicts can be created.

Cultural conflicts caused by religions and customs: Religion and belief condense the history and culture of a nationality. Different religions have different tendencies and taboos, which influence the way people, understand things, code of conduct, and values.

Cultural conflicts caused by the rigid corporate culture: Some enterprises seldom concern about the integration between corporate culture and the culture of host country. The staff in the company, especially the managers, follows the beaten track and is not willing to change; they follow the original corporate culture, neglect and even disregard the local culture and its influence towards their overseas operation

Relation between Management and Culture. Culture is of great importance to management. The management efficiency depends on the cultural parameters such as value system, management philosophy, etc. Management develops and manifests with the development of culture. Management is different among different cultures, and culture has its great functions on management.

The relation between management and culture is: culture is developed based on a certain degree of social productive forces, and management is a part of human culture. On one hand management develops with the development of culture, on the other hand it promotes cultural development.

Culture is a kind of management tool: In corporate management, culture becomes one of the management tools in form of "corporate culture". Construction of corporate culture is a kind of management tool for enterprises to enhance cohesion and increase competitiveness. Today more and more corporations realize the significance of the construction of the corporate culture, and many transnational companies saturate their own culture in the daily management, consider this as a competitive advantage.

Management is a kind of culture: As Peter F. Dracker said, "Management is not just a science, or a culture with its own values, beliefs, tools and languages." Management is part of the culture, management reflects culture in corporate management, different management style and management philosophy reflects the different cultures. Different cultures have different styles of management mode and management system. This is the research of cross-cultural management.

The coexistence of Management and culture: Management and cultural coexistence is that management develops and manifests with the development of culture, the development of management is impacted and determined by the direction, level and scale of the cultural development, meanwhile, the development of management influences the development of culture. For instance, the corporate culture generates and forms in a certain cultural context, after forming the corporate culture enriches the cultural connotation.

Cross-Cultural Management. Cross-culture means two groups of people with different cultures affect each other. The cross-cultural management is: when the different cultural groups have conflicts, every functional department applies corresponding cultural integrated measures, in order to solve the conflicts and to attain the goal of corporative management effectively. Cross-cultural management simply refers to the management of people, objects, matter involving different cultural backgrounds. Specifically, it requires the managers to change the traditional management concept of one culture, and shift management to understanding of cultural differences. They should make use of cultural synergy to 
overcome the difficulties which multi-cultural and cultural differences bring about, and give full play to the potentials and advantages of multiculturalism and cultural differences, to make the multinational companies more dynamic and vigorous.

\section{Solve the Problems Caused by Cultural Differences}

Measures to Minimize Cultural Differences and Narrow Cultural Gap Must be Taken into Account by Multinational Companies' Executives. The influence of cultural differences is not all that negative; they can also bring competition advantages to multinational companies, and add flexibility to enterprises. Measures must be taken to minimize cultural differences and narrow cultural gap.

The joint venture is to solve the problem of cultural conflict, must be the formation of shared values. In order to improve communication effects to understand the reaction of others would have to obtain other people how to perceive some of our concepts. If the understanding of how the performance of their own cultural communication style quite clear, we are better able to understand the reactions of others, transferred to another scenario from a communicative situation can be made in the way of communication necessary adjustments.

Cultivate Their Feelings Resonate. Means to put you to appreciate the joy of others and the situation, resulting in emotional resonance. To resonate, we must first recognize the differences between different cultures, and the only way to find the direction and the starting point. Secondly, a correct understanding of themselves, eliminate the ethnocentric prejudice, the elimination of the state of phase separation of the self and the environment. Third, we must stand on the receiver of the message that standing on each other's position looks at the problem, not only to consider the issue from their positions. The only way to establish a resonance in the process of cross-cultural communication.

Cultural Integration. The most effective way to address cultural differences and cultural differences within the enterprise to achieve cultural integration of the different cultures within the enterprise. The so-called cultural integration is intercultural recognized, valued on the basis of the differences between each other, respect each other and complement each other, co-ordination, thus forming a unity, a new organizational culture unified culture than strong stability. Cultural integration is fully aware of the similarities and differences between different cultures, not neglect and repression of cultural differences, but through fusion to form their own culture, to absorb the advanced management ideas and concepts developed countries and make it the best choice to adapt to their own national conditions. So we should be cultural differences as a resource, a management wealth, can not be regarded as an obstacle, because of different cultural views and perspectives can increase to solve problems unique ideas and solutions.

Implementation of the Combined System of the Rule of Man and the Rule of Law. The so-called rule of man is human-oriented management, people-oriented management; managers in the management of attention and care, caring subordinates, others to be honest, enthusiastic, and at the same time manage to have a human face, when necessary to pay attention to the mood of the workers. When to take some measures to avoid means too tough, as the case may take certain modifications. This is traditional management thinking.

The legal system is stressed that the company's management system. First, the company developed a strict set of rules and regulations, management, all in accordance with the rules and regulations do not exist any modifications. With the improvement of the management hierarchy, the rule of law in this management is increasingly becoming a trend. The rule of law to avoid the uncertainty and the actual management of the ruling by man difficult to master, a clear idea of the rule of law management, external, unbiased results with predictability, fairness.

The rule of law and the rule of man should be effectively combined to play both the favorable aspects to avoid its disadvantages. So as to avoid confusion due to cultural differences and the rule of man, in this there are a variety of cultural enterprises should pay more attention to the management of the rule of law. China has joined the WTO, the wave of the world economy, the cultural differences is not just multinationals facing, whether joint venture, state-owned enterprises, are going to encounter this kind of problem, so we have to prepare for, and win the cultural conflict this battle. If you can successfully break through the cultural differences, the cooperation will have a better future. 


\section{Summary}

Cultural difference is the problem that Daimler Co. Limited and Beijing Automotive Holdings Corp. will inevitably encounter in future cooperation, we should prepare mentally as early as possible, so that we can respond freely to solve problems and the cooperation can proceed successfully when faced with conflict in the future, this is not only viable to one side, but also crucial to the entire cooperation as a whole. China has entered WTO in the wave of the world economy; cultural difference is not just a problem that multinationals have to face; both joint ventures and state-owned enterprises will encounter this kind of problem, so we have to prepare for, and win this battle of cultural conflict.

\section{References}

[1] Alder, N.J. (1986). International Dimension of Organization Behavior. Boston: Wadsworth.

[2] Argyle, M. (1982). Inter-cultural Communication, New York: Pergamon Press.

[3] Blyton, P. (1989). Time, Work, and Organization, New York: Routledge.

[4] Bond, M.H. (1991). Beyond Chinese Face: Insight from Psychology, Hong Kong: Oxford University Press.

[5] Chaney, L.H., and Martin, J. S. (1975). Intercultural Business Communication. New York:

[6] Bobbs-Merill Company.

[7] Dennison, D. (1990). Corporate Culture and Organizational Effectiveness. New York: John Wiley

[8] Foster, D.A. (1992). Bargaining Across Borders. New York: McGraw-Hill: 265-267

[9] Hall, E. T. (1959). The Silent Language. NewYork: Doubleday.

[10] Hall, E. T. (1969). The Hidden Dimension: Man's Use of Space in Public and Private.

[11]London: Bodley Head.

[12]Hall,E.T. (1976). Beyond Culture. Garden City, NY: Doubleda. 
